\title{
COMPOSIÇÃO E DISTRIBUIÇÃO ESPAÇO-TEMPORAL DE ANUROS NO CARIRI PARAIBANO, NORDESTE DO BRASIL
}

\author{
Washington Luiz da Silva Vieira ${ }^{1}$,Cristina Arzabe ${ }^{2}$ \& Gindomar Gomes Santana ${ }^{1}$ \\ ${ }^{1}$ Programa de Pós-Graduação em Ciências Biológicas (Área de Concentração em Zoologia), Universidade Federal da Paraíba, CCEN, Departamento de \\ Sistemática e Ecologia (DSE), Coleção de Herpetologia, João Pessoa, Paraíba, CEP. 58059-900. \\ ${ }^{2}$ Embrapa Meio Norte/UEP BR 343, Km35; Caixa Postal 341. Parnaíba, Piauí. CEP: 64200-970. \\ E-mails: wlsvieira@yahoo.com.br; arzabe@cpamn.embrapa.br; gindomar@yahoo.com.br
}

\section{RESUMO}

O presente estudo teve como objetivo caracterizar a estrutura e a composição da anurofauna associada a diferentes corpos d'água temporários em uma área de caatinga do nordeste brasileiro. As coletas de dados consistiram em buscas intensivas na área, percorrendo-se as margens dos corpos d'água e áreas adjacentes. Na composição da anurofauna, foram registradas 16 espécies, pertencentes a 11 gêneros e sete famílias (Bufonidae, 2 espécies; Hylidae, 4; Leptodactylidae, 4; Leiuperidae, 3; Cycloramphidae, 1; Microhylidae,1 e Pipidae, 1). Algumas destas espécies apresentam estreita relação com o bioma Caatinga. Em relação às estratégias reprodutivas, a anurofauna apresentou período de reprodução restrito à estação chuvosa, turno de vocalização exclusivamente noturno e cinco modos reprodutivos distintos, sendo que 43,7\% das espécies registradas depositaram ovos em ninhos de espuma, diretamente sobre a superfície da água ou em tocas subterrâneas construídas pelo macho.

Palavras-chave: Anuros, Caatinga, Ecologia de Comunidades.

\begin{abstract}
COMPOSITION, AND SPATIAL-TEMPORAL DISTRIBUTION OF ANURANS IN THE CARIRI PARAIBANO, NORTHEAST BRAZIL. The objective of the present study was to characterize the structure and the composition of an anuran assemblage associated to different temporary ponds in a Caatinga area in Northeast Brazil. The data were obtained through intensive search in the area, investigating the margins of water bodies and adjacent areas. In the anuran composition, it was registered 16 species distributed in 11 genera and seven families (Bufonidae, 2 species; Hylidae, 4; Leptodactylidae, 4; Leiuperidae, 3; Cycloramphidae, 1; Microhylidae, 1 e Pipidae, 1). Some of these present a strong correlation with the Caatinga. The anurans presented reproduction restricted to the rainy season, an exclusive nocturnal calling activity, and five distinct reproductive modes, $43.7 \%$ of the recorded species deposited eggs in foam nest, directly on the water surface or in subterranean burrows built by the male.
\end{abstract}

Keywords: Anurans, Caatinga, Community ecology

\section{INTRODUÇÃO}

A caatinga propriamente dita é uma vegetação seca que perde as folhas durante a estação de estiagem (Ross 1998) e que se estende do Piauí até o norte de Minas Gerais, ocupando uma área de $734.478 \mathrm{~km}^{2}$ (MMA 2002). O domínio das depressões interplanálticas semi-áridas do Nordeste é revestido por diferentes tipos de caatingas com fraca decomposição da necromassa vegetal, freqüentes afloramentos rochosos, solo pedregoso, drenagens intermitentes e numerosos campos de inselbergs (Ab’Sáber 1970). As precipitações nas de- pressões interplanálticas correspondem a médias que variam entre 200 e $700 \mathrm{~mm}$ e as temperaturas médias anuais estão na ordem de $25^{\circ}-27^{\circ} \mathrm{C}$. A forte deficiência hídrica sazonal faz com que o período úmido seja do tipo sub-úmido e que o período seco seja quase que totalmente árido, implicando num período seco de cinco a sete meses a cada ano e típico de regiões semiáridas ou sub-desérticas (Ab’Sáber 1977).

Atualmente, são conhecidas 6.240 espécies de anfíbios (Amphibiaweb 2007, Frost 2007) distribuídas principalmente nos trópicos e regiões temperadas, e ocorrendo inclusive em algumas ilhas oceânicas, es- 
pecialmente aquelas do sul do Oceano Pacífico e nos desertos, dosmaisbrandosaosmaisextremos(Duellman \& Trueb 1994). A ordem Anura possui 5.504 espécies e é constituída pelos sapos, rãs e pererecas, sendo este grupo o mais abundante entre os anfíbios (Amphibiaweb 2007, Frost 2007). No Brasil, são encontradas 789 espécies de anuros distribuídas em 10 famílias, sendo que cerca de $60 \%$ são endêmicas do território brasileiro (Lewinsohn \& Prado 2002, SBH 2007).

O conhecimento sobre a diversidade da maioria dos grupos de organismos nos grandes biomas brasileiros é insuficiente. De maneira geral, o bioma melhor conhecido e amostrado é a Mata Atlântica e os menos explorados são o Cerrado, o Pantanal e a Caatinga. É fato indiscutível que, dos grandes biomas brasileiros, a Caatinga ainda é o menos conhecido (Lewinsohn \& Prado 2002). Este bioma não é pobre em espécies e em endemismo pois, apesar de ser ainda muito mal amostrado, sabe-se que é mais diverso que qualquer outro bioma no mundo exposto às mesmas condições de clima e solo (MMA 2002).

Heyer (1988) considerou a Caatinga um dos biomas brasileiros mais pobremente amostrados em relação a anurofauna, e a falta de revisões sobre a sistemática de anuros neotropicais e a escassez de informações naturalísticas sobre a Caatinga representam empecilhos adicionais para estudos nesta região. Segundo Rodrigues (2002), são conhecidas atualmente 49 espécies de anfíbios anuros nas localidades com a feição característica das caatingas semi-áridas. Um levantamento preliminar realizado por esse autor, tomando por base a coleção do Museu de Zoologia da USP, mostra que existem espécimes registrados para 150 localidades assim distribuídas: Bahia, 53; Pernambuco, 27; Paraíba, 19; Ceará, 18; Rio Grande do Norte, 7; Piauí, 6 e Alagoas, 6. Esse levantamento também indicou que não há registro no Museu de Zoologia da USP de anfíbios das manchas de caatinga do norte de Minas Gerais.

Em comparação com o restante do Brasil, a escassez de inventários faunísticos no Nordeste mostra-se especialmente dramática, sendo que apenas 10\% dos inventários publicados concentram-se nesta região (Lewinsohn \& Prado 2002). Para reverter este quadro e visando dar suporte a estratégias regionais de conservação da diversidade de anfíbios em áreas prioritárias para a conservação da Caatinga, Borges-
Nojosa \& Arzabe (2005) analisaram dados coletados em três diferentes estados (PE, PB e CE).

Com base nos estudos sobre a herpetofauna da Caatinga, a criação de áreas protegidas foi uma ação recomendada para dezenove localidades, incluindo o Cariri Paraibano. Todas estas áreas estão inseridas em regiões de elevada diversidade, as quais abrigam importantes extensões de caatinga bem preservadas, com alguns endemismos e distribuições relictuais (Rodrigues 2002). Desta forma, este estudo representa parte do esforço conjunto de pesquisadores envolvidos no Programa de Pesquisas Ecológicas de Longa Duração (PELD) - Sítio Caatinga, na busca de informações sobre a estrutura e funcionamento do bioma Caatinga e de sua fauna associada. Nesse sentido, o objetivo desse trabalho foi caracterizar a estrutura, composição e uso do habitat em uma taxocenose de anuros associada a ambientes aquáticos temporários em área de caatinga no Cariri Paraibano.

\section{MATERIAIS E MÉTODOS}

\section{CARACTERIZAÇÃO DAS ÁREAS DE ESTUDO}

A microrregião do Cariri Paraibano é uma subregião do Planalto da Borborema. Esta microrregião encontra-se na porção centro sul do estado da Paraíba, com elevações que variam de 400 a $600 \mathrm{~m}$, ocupando uma área de $13.845 \mathrm{~km}^{2}$. O Cariri incorpora-se à paisagem da caatinga paraibana, como uma das áreas mais secas do país (Cabral 1997), de clima semiárido, onde imperam diferentes tipos de vegetação do domínio fitogeográfico das Caatingas e um ambiente seco com drenagem intermitente (Ab’Sáber 1969).

Este estudo foi realizado entre os anos de 2002 e 2004 nos municípios de Boa Vista e São João do Cariri, situados respectivamente a 173 e 203km da capital,João Pessoa, no sentido oeste-sudeste, na microrregião do Cariri Paraibano. No município de São João do Cariri, os trabalhos de campo foram realizados na Estação Experimental de São João do Cariri - EESJC (07025’S e 36³0’W), Fazenda Olho D'água (07022'S e 36⒊'W) e Riacho Aveloz (07²8’S e 36³1’W), e no município de Boa Vista, na área do entorno da Lagoa do Serrote (07018'S e $\left.36^{\circ} 20^{\prime} \mathrm{W}\right)$. Nessas áreas, a estação seca pode durar até 10 meses consecutivos, com alguns anos praticamente sem chuvas. A precipitação anual média está em 


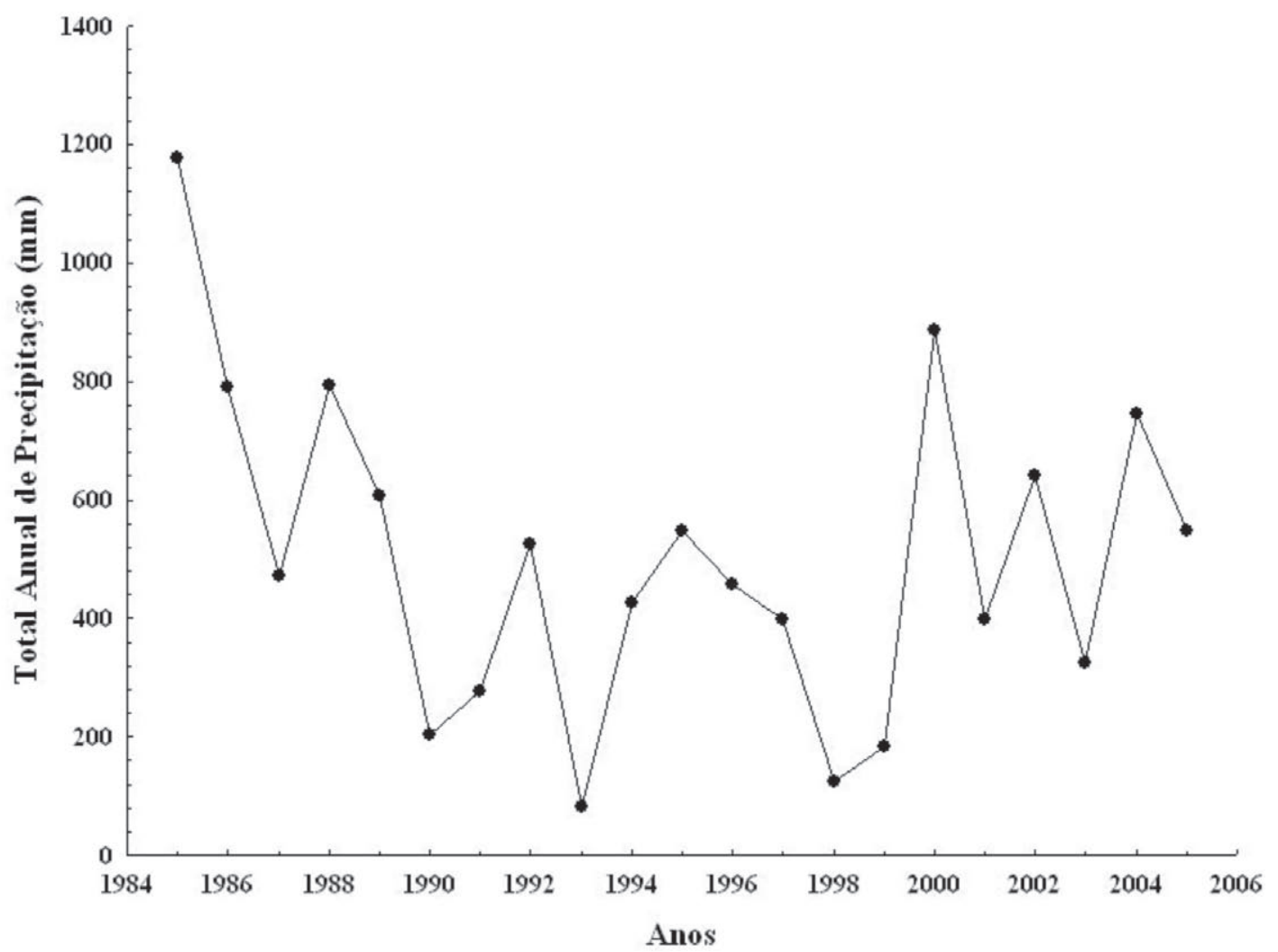

Figura 1. Dados pluviométricos referentes ao período de janeiro de 1985 a agosto de 2006 para as áreas de estudo (fonte: Estação Metereológica de São João do Cariri, Paraíba, Brasil).

torno de 387mm, sendo as maiores médias históricas de precipitação concentradas nos meses de janeiro, fevereiro e março (Figura 1).

A vegetação encontrada nas áreas de estudo classifica-se como uma caatinga arbustiva, com forte densidade de cactáceas e bromeliáceas (Agra 1996). A macambira-de-pedra (Bromelia laciniosa Mart. ex Schult. f.) e outras plantas xerófilas ocorrem com abundância sobre os afloramentos rochosos (Stevaux 1993). Em um dos extremos, a vegetaçãoé representada por uma mata caducifólia espinhosa com cactáceas arbóreas, intercaladas por árvores típicas como o pereiro (Aspidosperma pyrifolium Mart.), as juremas (Mimosa spp.) e algumas árvores de distribuição mais esparsa que preservam suas folhas o ano inteiro, como os juazeiros (Ziziphus joazeiro Mart.) (Agra 1996).

Nas áreas estudadas formam-se vários corpos d'água temporários durante o período de chuvas, sendo que dez deles foram selecionados para a realização do inventário e obtenção de dados ecológicos da anurofauna. A caracterização destes ambientes foi realizada através de coleta e identificação de material botânico fértil, além de observações gerais sobre os corpos d'água estudados (hidroperíodo, profundidade e área).
A vegetação do entorno dos sítios reprodutivos foi classificada quanto ao seu porte (arbóreo, arbustivo e herbáceo) e quanto a sua localização em relação à água (plantas emergentes, flutuantes de meio e de borda). Exemplares de material botânico fértil foram amostrados conforme procedimentos de rotina, e identificados por comparação com exemplares depositados no Herbário Lauro Pires Xavier (JPB) do Departamento de Sistemática e Ecologia da Universidade Federal da Paraíba. As médias mensais referentes à temperatura e precipitação foram obtidas na EESJC.

\section{COLETA E OBSERVAÇÕES DOS ANIMAIS EM CAMPO}

Entre os meses de junho e dezembro de 2002 foram realizadas viagens de reconhecimento da área, determinação dos sítios de observação e extensão do período diário de amostragem, somando 120 horas de campo. A coleta de dados foi então determinada como mensal no período chuvoso e bimensal, no período de estiagem. Os dados foram coletados entre os meses de janeiro de 2003 e dezembro de 2004, sendo 
cada excursão de campo de quatro dias, totalizando 13 excursões e 546 horas de campo. A captura e a observação de espécimes foram realizadas no período diurno, entre 8:00 e 12:00 horas, e no noturno, entre 17:30 horas e 1:00 hora da manhã do dia seguinte.

As coletas diurnas consistiram em caminhadas em torno dos corpos d'água com o objetivo de detectar a presença de desovas, girinos, jovens recém-metamorfoseados e indivíduos adultos, ocultos nas irregularidades do ambiente estudado. Para isso foram inspecionados microhabitats como troncos e galhos caídos, fendas no solo e nas rochas, folhiço e touceiras de cactáceas e macambiras próximos aos corpos d’água. As coletas e observações noturnas de anfíbios consistiram em buscas intensivas na área, onde foram realizadas caminhadas percorrendo as margens dos corpos d’água, utilizando-se lanterna de cabeça e captura manual dos espécimes. Os exemplares capturados foram depositados na Coleção de Herpetologia do Departamento de Sistemática e Ecologia da Universidade Federal da Paraíba.

Foram utilizados os seguintes parâmetros para caracterizar as atividades reprodutivas das espécies de anuros registradas: a) presença de machos em vocalização b) pares em amplexo; b) presença de desovas e c) presença de girinos nos sítios de reprodução. Foi possível determinar a preferência por determinados microambientes a partir das observações dos adultos e de seus locais de ocupação ou sítios de reprodução. O registro dos diferentes modos reprodutivos seguiu os critérios propostos por Haddad \& Prado (2005).

\section{ANÁLISE DOS DADOS}

Para avaliar a similaridade entre as espécies que utilizaram diferentes sítios de vocalização, foi utilizado o Coeficiente de similaridade de Sørensen e posterior análise de agrupamento por Unweighted Pair-Group Method using arithmetic Average (UPGMA) (Krebs 1989). Para a análise dos resultados obtidos foi utilizado o programa Statsoft.

\section{RESULTADOS E DISCUSSÃO}

\section{COMPOSIÇÃO DA ANUROFAUNA}

Dezesseis espécies pertencentes a sete famílias (Bufonidae, 2 espécies; Hylidae, 4; Leptodactylidae, 4; Leiuperidae, 3; Cycloramphidae, 1; Microhylidae,
1 e Pipidae, 1), distribuídas em onze gêneros, foram registradas nas áreas estudadas. Leptodactylidae e Hylidae foram às famílias com o maior número de espécies, sendo as mais abundantes na região (Tabela I), ambas correspondendo a $25 \%$ do total, seguidas da família Leiuperidae, com 18,7\%. A predominância de espécies das famílias Hylidae e Leptodactylidae coincide com o padrão observado para a região Neotropical (sensu Duellman 1978). A anurofauna estudada é constituída por espécies típicas das formações abertas da América do Sul e espécies de ampla distribuição geográfica, tanto em formações abertas como também florestadas.

A anurofauna das áreas estudadas é formada por espécies que foram registradas anteriormente em outros estudos na Caatinga. Cascon (1987) registrou 18 espécies na Fazenda Bravo, município de Cabaceiras, também no Cariri Paraibano, e Arzabe (1999) encontrou 16 espécies em Maturéia e 12 em São José do Bonfim, também no estado da Paraíba. Arzabe et al. (2005), estudando a região do Curimataú, registraram 21 anfíbios (20 anuros e uma cecília), com predomínio de espécies registradas na área com vegetação do tipo mata seca e baixa riqueza de espécies na vegetação do tipo caatinga arbustiva-arbórea.

Comparando-se as espécies detectadas nas áreas aqui estudadas com esses dados anteriores, observase que 12 delas foram registradas na Fazenda Bravo, 10 em Maturéia e seis em São José do Bonfim (Tabela II). Observa-se, de um modo geral, que não houve uma grande diferença no número de espécies entre estas áreas, o que pode ser devido ao fato da anurofauna destas localidades ser composta por espécies comuns na Caatinga.

A ocorrência da espécie Leptodactylus caatingae no estado da Paraíba foi registrada por Vieira et al. (2006). Estes autores compararam seus espécimes com aqueles provenientes da Fazenda Bravo e concluíram que Leptodactylus latinasus registrada para esta localidade por Cascon (1987) trata-se de fato de $L$. caatingae, conforme a descrição fornecida por Heyer \& Juncá (2003). Semelhantemente, os espécimes relatados por Arzabe (1999) e Arzabe et al. (2005) como pertencentes a Physalaemus kroyeri, respectivamente para as localidade de Maturéia, Parque Estadual Pedra da Boca/Araruna e Fazenda Cachoeira de Capivara/Cacimba de Dentro são, na verdade, pertencentes a espécie Physalaemus albifrons. 
Tabela I. Lista de espécie e famílias de anfíbios anuros registrados durante o período de janeiro de 2003 a dezembro de 2004 nas áreas estudadas em São João do Cariri e Boa Vista, Paraíba, Brasil, e suas respectivas abundâncias relativas.

\begin{tabular}{lcc}
\hline Espécies & $\begin{array}{c}\text { Abundância relativa/ } \\
\text { espécie (\%) }\end{array}$ & $\begin{array}{c}\text { Abundânciarelativa/ } \\
\text { Família(\%) }\end{array}$ \\
\hline Rhinella granulosa Spix, 1824 & 8 & Bufonidae \\
Rhinella jimi (Stevaux 2003) & 5 & 12,50 \\
Proceratophrys cristiceps (Müller 1884) & 3 & Cycloramphidae \\
& 5 & Hylidae \\
Corythomantis greeningi Boulenger, 1896 & 25 & 25,00 \\
Hypsiboas raniceps Cope, 1862 & 8 & \\
Phyllomedusa nordestina Caramaschi, 2006 & 8 & Leptodactylidae \\
Scinax x-signatus (Spix 1824) & 5 & 25,00 \\
Leptodactylus caatingae Heyer \& Juncá, 2003 & 3 & \\
Leptodactylus fuscus (Schneider 1799) & 15 & Leiuperidae \\
Leptodactylus ocellatus (Linnaeus 1758) & 4 & 18,75 \\
Leptodactylus troglodytes (Lutz 1926) & 5 & Pipidae \\
Physalaemus albifrons (Reinhardt \& Lütken 1862) & 14 & 6,25 \\
Physalaemus cicada Bokkerman, 1966 & 13 & Microhylidae \\
Pleurodema diplolister (Peters 1870) & 1 & 6,25 \\
Pipa carvalhoi (Miranda - Ribeiro 1937) & & \\
Dermatonotus muelleri (Boettger 1885) & 1 & \\
\end{tabular}

UTILIZAÇÃO DOS SÍTIOS DE REPRODUÇÃO E MICROAMBIENTES

A grande maioria dos ambientes aquáticos surge como resultado das precipitações durante o período de chuvas na região, podendo apresentar uma profundidade variando entre 20 e $80 \mathrm{~cm}$ e acumular água por um período de um a seis meses. Os ambientes aquáticos temporários utilizados como sítios de reprodução foram os seguintes:

T1: Poça temporária localizada na Fazenda Olho D’água (07²2'S e 36³1’W), município de São João do Cariri. Este corpo d'água apresentou uma área de $141 \mathrm{~m}^{2}$, profundidade máxima de $62 \mathrm{~cm}$, tempo máximo com água de três meses. A vegetação do entorno e do centro da lagoa inclui plantas de porte arbóreo, herbáceo, além de cactáceas e bromeliáceas.

T2: Poça temporária localizada na Fazenda Olho D’água (07022's e 36³1’W), município de São João do Cariri. Este corpo d'água apresentou uma área de $175 \mathrm{~m}^{2}$, profundidade máxima de $70 \mathrm{~cm}$, tempo máximo com água de três meses. A vegetação do entorno e do centro da lagoa inclui plantas de porte arbóreo, representada predominantemente por Prosopis juliflora (Sw.) DC., herbáceo, além de cactáceas e bromeliáceas.

T3: Poça temporária localizada na Fazenda Olho D’água (07²2'S e 36 31'W), município de São João do Cariri. Este corpo d'água apresentou uma área de $18 \mathrm{~m}^{2}$, profundidade máxima de $20 \mathrm{~cm}$, tempo máximo com água um mês, com pouca vegetação na margem e no centro, sendo representada apenas por dez indivíduos de Prosopis juliflora.

T4: Poça temporária localizada na Fazenda Olho D’água (07²2's e 36³1'W), município de São João do Cariri. Este corpo d'água apresentou uma área de $357 \mathrm{~m}^{2}$, profundidade máxima de $50 \mathrm{~cm}$, tempo máximo com água seis meses. A vegetação do entorno e do centro da lagoa é constituída por espécies de porte arbóreo das famílias Leguminosae subfamília Caesalpinioideae, Leguminosae subfamília Mimosoideae e Apocynaceae; arbustivo, pertencente à família Euphorbiaceae, e plantas herbáceas das famílias Juncaceae, Cyperaceae e Poaceae, macrófitas aquáticas da família Nymphaeaceae, além de cactáceas e bromeliáceas.

T5: Poça temporária localizada na Fazenda Olho D’água (07²2’s e 36³1’W), município de 
Tabela II. Distribuição das espécies de anuros encontrados em cinco localidades no domínio da Caatinga no estado da Paraíba. SJC: São João do Cariri/ PB; CAB: Cabaceiras/PB; MAT: Maturéia/PB; SJB: São José do Bonfim/PB e BV: Boa Vista/PB.

\begin{tabular}{|c|c|c|c|c|c|}
\hline Família/Espécie & CAB & MAT & SJC & BV & SJB \\
\hline \multicolumn{6}{|l|}{ Bufonidae } \\
\hline Rhinella granulosa Spix, 1824 & $\mathrm{X}$ & & $\mathrm{X}$ & $\mathrm{X}$ & $\mathrm{X}$ \\
\hline Rhinella jimi Stevaux, 2002 & $\mathrm{X}$ & $\mathrm{X}$ & $\mathrm{X}$ & $\mathrm{X}$ & \\
\hline \multicolumn{6}{|l|}{ Hylidae } \\
\hline Corythomantis greeningi Boulenger, 1896 & $\mathrm{X}$ & & $\mathrm{X}$ & & \\
\hline Dendropsophus aff. nanus (Boulenger, 1889) & & & & & $\mathrm{X}$ \\
\hline Dendropsophus soaresi (Caramaschi \& Jim, 1983) & $\mathrm{X}$ & & & & $\mathrm{X}$ \\
\hline Hypsiboas creptans (Wied-Neuwied, 1824) & $\mathrm{X}$ & $\mathrm{X}$ & & & $\mathrm{X}$ \\
\hline Hypsiboas raniceps Cope, 1862 & & $\mathrm{X}$ & $\mathrm{X}$ & & $\mathrm{X}$ \\
\hline Phyllomedusa nordestina Caramaschi, 2006 & $\mathrm{X}$ & $\mathrm{X}$ & $\mathrm{X}$ & $\mathrm{X}$ & $\mathrm{X}$ \\
\hline Scinax pachychrus (Miranda-Ribeiro, 1937) & $\mathrm{X}$ & $\mathrm{X}$ & & & \\
\hline Scinax x-signatus (Spix, 1824) & $\mathrm{X}$ & & $\mathrm{X}$ & $\mathrm{X}$ & $\mathrm{X}$ \\
\hline \multicolumn{6}{|l|}{ Leiuperidae } \\
\hline Physalaemus albifrons (Spix, 1824) & $\mathrm{X}$ & & $\mathrm{X}$ & & $\mathrm{X}$ \\
\hline Physalaemus cicada Bokermann, 1966 & $\mathrm{X}$ & & $\mathrm{X}$ & & $\mathrm{X}$ \\
\hline Physalaemus cuvieri Fitzinger, 1826 & & $\mathrm{X}$ & & & $\mathrm{X}$ \\
\hline Pleurodema diplolister (Peters, 1870) & $\mathrm{X}$ & & $\mathrm{X}$ & $\mathrm{X}$ & $\mathrm{X}$ \\
\hline Pseudopaludicola sp. & & $\mathrm{X}$ & & & $\mathrm{X}$ \\
\hline \multicolumn{6}{|l|}{ Leptodactylidae } \\
\hline Leptodactylus caatingae Heyer \& Juncá, 2003 & $\mathrm{X}$ & & $\mathrm{X}$ & & \\
\hline Leptodactylus fuscus (Schneider, 1799) & & $\mathrm{X}$ & $\mathrm{X}$ & & $\mathrm{X}$ \\
\hline Leptodactylus ocellatus (Linnaeus, 1758) & $\mathrm{X}$ & & $\mathrm{X}$ & $\mathrm{X}$ & \\
\hline Leptodactylus syphax Heyer, 1983 & $\mathrm{X}$ & & & & \\
\hline Leptodactylus troglodytes A. Lutz, 1926 & $\mathrm{X}$ & $\mathrm{X}$ & $\mathrm{X}$ & $\mathrm{X}$ & $\mathrm{X}$ \\
\hline Leptodactylus vastus A. Lutz, 1930 & & $\mathrm{X}$ & & & $\mathrm{X}$ \\
\hline \multicolumn{6}{|l|}{ Cycloramphidae } \\
\hline Proceratophrys cristiceps (Muller, 1884 “1883”) & $\mathrm{X}$ & $\mathrm{X}$ & $\mathrm{X}$ & & \\
\hline \multicolumn{6}{|l|}{ Microhylidae } \\
\hline Dermatonotus muelleri (Boettger, 1885) & $\mathrm{X}$ & & $\mathrm{X}$ & & $\mathrm{X}$ \\
\hline \multicolumn{6}{|l|}{ Pipidae } \\
\hline Pipa carvalhoi (Miranda-Ribeiro, 1937) & $\mathrm{X}$ & $\mathrm{X}$ & & $\mathrm{X}$ & \\
\hline Número total de espécies & 18 & 12 & 16 & 9 & 16 \\
\hline
\end{tabular}

São João do Cariri. Este corpo d'água apresentou uma área de $471 \mathrm{~m}^{2}$, com profundidade máxima de $70 \mathrm{~cm}$, tempo máximo com água cinco meses. A vegetação do entorno e do centro da lagoa é constituída por espécies de porte arbóreo das famílias Leguminosae subfamília Caesalpinioideae e Leguminosae subfamília Mimosoideae, porte arbustivo da família Euphorbiaceae, herbáceas das famílias Juncaceae, Cyperaceae e Poaceae, plantas flutuantes da família Nymphaeaceae; e próximas das margens e no interior da mesma são encontradas touceiras de bromeliáceas e cactáceas.

T6: Reservatório artificial de água formado a partir da escavação de uma antiga pedreira localizada na EESJC (07²2'S e 36³1'W), município de São João do Cariri. Este ambiente aquático possui uma área de $41 \mathrm{~m}^{2}$, profundidade máxima de $48 \mathrm{~cm}$, tempo máximo com água seis meses. As suas margens possuem pouca vegetação, com predomínio de cactáceas. É encontrada uma espécie de porte arbustivo, Cnidoscolus urens (L.) Arthur (Euphorbiaceae), duas de porte herbáceo, Dioclea grandiflora Mart. ex Benth. (Leguminosae) e Portulaca pilosa L. (Portulacaceae), além de bromeliáceas nas bordas e no meio deste corpo d'água, respectivamente.

T7: Poça temporária localizada na EESJC 
(07022’S e 36³1’W), município de São João do Cariri. Este corpo d'água possui uma área de $188 \mathrm{~m}^{2}$, profundidade máxima de $50 \mathrm{~cm}$, tempo de duração com água três meses, temperatura da água entre $25^{\circ}$ e $32^{\circ} \mathrm{C}$. O fundo com solo pedregoso, com cascalho em alguns trechos e bastante argiloso em outros. A vegetação do entorno e do centro da lagoa é formada por espécies de porte arbóreo pertencentes às famílias Leguminosae subfamília Caesalpinioideae e Leguminosae subfamília Mimosoideae. Plantas de porte arbustivo da família Euphorbiaceae, e herbáceas das famílias Juncacae, Cyperaceae e Nymphaeacae, com bromeliáceas e cactáceas localizadas nas margens e interior deste corpo d'água.

L: Lagoa temporária chamada 'Lagoa do Serrote' (07²18’S e 36²0’W), município de Boa Vista, na margem direita da rodovia federal BR-412 no sentido Boa Vista-São João do Cariri. Este corpo d'água possui profundidade de até $2 \mathrm{~m}$. A vegetação do entorno é formada por cactáceas, bromeliáceas, espécies de porte arbóreo, arbustivo e herbáceo, além de macrófitas aquáticas flutuantes e emergentes em seu interior.

P: Açude de porte médio com caráter permanente chamado ‘Açude dos Namorados' (07023's e $36^{\circ} 32^{\prime} \mathrm{W}$ ), com profundidade máxima superior a
$6 \mathrm{~m}$ e capacidade $2.118 .980 \mathrm{~m}^{3}$ de água, localizado no município de São João do Cariri. A vegetação do entorno é formada por poucas árvores, sendo representadas por espécies de porte arbóreo, arbustivo e herbáceo, além de macrófitas aquáticas flutuantes e emergentes em seu interior.

R: Riacho temporário chamado 'Riacho Aveloz' $\left(7^{\circ} 26^{\prime} \mathrm{S}\right.$ e $\left.36^{\circ} 29^{\prime} \mathrm{W}\right)$, um afluente o rio Taperoá, localizado a 6km de distância de São João do Cariri. No trecho estudado, a vegetação caracteriza-se por apresentar árvores de grande porte, arbustos, ervas, bromeliáceas e cactáceas.

A distribuição das espécies nos sítios reprodutivos variou de três espécies, no sítio T3, até doze espécies nos sítios T4 e T5. A maioria das espécies mostrouse bastante generalista, não tendo preferência por um determinado sítio reprodutivo (Tabela III).

A maioria das espécies terrestres mostrou-se abundante e ocupando um maior número de ambientes aquáticos temporários, utilizados como sítios de reprodução. Rhinella granulosa, Leptodactylus ocellatus, Pleurodema diplolister e Physalaemus cicada mostraram-se em maior abundância entre as espécies terrestres, enquanto Phyllomedusa nordestina e Scinax $x$-signatus foram as mais abundantes entre as espécies arborícolas e também

Tabela III. Distribuição das 16 espécies de anfíbios anuros encontradas em dez sítios reprodutivos estudados em São João do Cariri e Boa Vista, Paraíba, Brasil, durante o período de janeiro de 2003 a dezembro de 2004. T= poça temporária; L= Lagoa do Serrote (Lagoa temporária); P= Açude dos Namorados; R= Riacho Aveloz (rio temporário).

\begin{tabular}{|c|c|c|c|c|c|c|c|c|c|c|}
\hline Espécies & T1 & T2 & T3 & T4 & T5 & T6 & T7 & $\mathbf{L}$ & $\mathbf{P}$ & $\mathbf{R}$ \\
\hline Rhinella granulosa & $\mathrm{X}$ & $\mathrm{X}$ & & $\mathrm{X}$ & $\mathrm{X}$ & $\mathrm{X}$ & $\mathrm{X}$ & $\mathrm{X}$ & $\mathrm{X}$ & $\mathrm{X}$ \\
\hline Rhinella jimi & $\mathrm{X}$ & $\mathrm{X}$ & & $\mathrm{X}$ & & $\mathrm{X}$ & & $\mathrm{X}$ & $\mathrm{X}$ & $\mathrm{X}$ \\
\hline Corythomantis greeningi & & & & & $\mathrm{X}$ & $\mathrm{X}$ & & & & \\
\hline Hypsiboas raniceps & $\mathrm{X}$ & & & & & & & & $\mathrm{X}$ & \\
\hline Phyllomedusa nordestina & $\mathrm{X}$ & $\mathrm{X}$ & & $\mathrm{X}$ & $\mathrm{X}$ & $\mathrm{X}$ & $\mathrm{X}$ & $\mathrm{X}$ & $\mathrm{X}$ & \\
\hline Scinax $x$-signatus & & $\mathrm{X}$ & & $\mathrm{X}$ & $\mathrm{X}$ & $\mathrm{X}$ & $\mathrm{X}$ & $\mathrm{X}$ & $\mathrm{X}$ & \\
\hline Leptodactylus caatingae & & & & $\mathrm{X}$ & $\mathrm{X}$ & & $\mathrm{X}$ & & & \\
\hline Leptodactylus fuscus & $\mathrm{X}$ & & & $\mathrm{X}$ & $\mathrm{X}$ & & $\mathrm{X}$ & $\mathrm{X}$ & & \\
\hline Leptodactylus ocellatus & $\mathrm{X}$ & $\mathrm{X}$ & & $\mathrm{X}$ & $\mathrm{X}$ & $\mathrm{X}$ & $\mathrm{X}$ & $\mathrm{X}$ & $\mathrm{X}$ & $\mathrm{X}$ \\
\hline Leptodactylus troglodytes & & $\mathrm{X}$ & & $\mathrm{X}$ & $\mathrm{X}$ & & $\mathrm{X}$ & $\mathrm{X}$ & $\mathrm{X}$ & $\mathrm{X}$ \\
\hline Physalaemus albifrons & $\mathrm{X}$ & $\mathrm{X}$ & $\mathrm{X}$ & $\mathrm{X}$ & $\mathrm{X}$ & & $\mathrm{X}$ & & & \\
\hline Physalaemus cicada & $\mathrm{X}$ & $\mathrm{X}$ & $\mathrm{X}$ & $\mathrm{X}$ & $\mathrm{X}$ & & $\mathrm{X}$ & & & \\
\hline Pleurodema diplolister & $\mathrm{X}$ & $\mathrm{X}$ & $\mathrm{X}$ & $\mathrm{X}$ & $\mathrm{X}$ & & & $\mathrm{X}$ & & \\
\hline Proceratophrys cristiceps & & & & $\mathrm{X}$ & $\mathrm{X}$ & & $\mathrm{X}$ & & & \\
\hline Dermatonotus muelleri & & & & $\mathrm{X}$ & $\mathrm{X}$ & $\mathrm{X}$ & & & & \\
\hline Pipa carvalhoi & & & & & & & & $\mathrm{X}$ & & \\
\hline Total & 8 & 8 & 3 & 12 & 12 & 6 & 8 & 9 & 7 & 4 \\
\hline
\end{tabular}


as que ocuparam um maior número de corpos d'água para a reprodução.

Foram registrados nos meses de maior precipitação dez indivíduos machos de $R$. granulosa vocalizando no sítio T4, dez de Hypsiboas raniceps no sítio P e apenas um macho desta espécie no sítio T1. Contudo, não foram registrados indivíduos em amplexo ou desovas, o que não permite assegurar que estas espécies tiveram sucesso reprodutivo durante o período estudado. Segundo Scott \& Woodward (1994), a vocalização em anuros não significa exatamente reprodução, tornando-se necessária à observação de amplexos, desovas, larvas ou outros indícios de reprodução para determinar o período e o sucesso reprodutivo de uma determinada espécie.

O maior número de espécies foi registrado nos sítios T4 e T5 (Tabela III). Nestes dois sítios, a profundidade (50 e $70 \mathrm{~cm}$, respectivamente), o tempo de permanência com água relativamente longo (6 e 5 meses, respectivamente) e a estrutura da vegetação do entorno e de dentro das lagoas temporárias, parecem contribuir favoravelmente para os valores de riqueza de espécies registrados.

A ocorrência de muitas espécies em certos sítios reprodutivos e de uma única espécie na Lagoa do Serrote, como é o caso de Pipa carvalhoi, pode ocorrer em função da estrutura da vegetação e durabilidade da poça. Phyllomedusa nordestina, por exemplo, precisa de folhas para depositar a desova e utiliza o estrato arbóreo como microambiente para a vocalização. $P$. carvalhoi vocaliza e realiza todo o seu comportamento de corte, como amplexo e deposição dos ovos no dorso na fêmea, dentro da água. Além disso, de acordo com Aichinger (1987), a durabilidade da poça é uma variável ambiental que determina o tempo necessário para que o girino possa completar sua metamorfose. Bernarde \& Anjos (1999) também sugeriram que a segregação das espécies nas comunidades pode ocorrer em função da estrutura da vegetação e da durabilidade da poça.

Foram utilizados vários microambientes como sítios de vocalização pelas espécies registradas nos ambientes aquáticos estudados. A grande maioria das espécies estudadas vocalizou no solo próximo à água (66,6\%), sendo os leptodactilídeos e os hilídeos os que ocuparam um maior número de microambientes como sítios de vocalização (Tabela IV). Apenas $P$. carvalhoi não compartilhou com nenhuma outra espécie o microambiente utilizado para a vocalização, isto devido ao fato desta espécie ser predominantemente aquática.

A elevada sobreposição na utilização dos sítios de

Tabela IV. Diferentes microambientes utilizados como sítios de vocalização pelas espécies de anfíbios anuros registradas em São João do Cariri e Boa Vista, Paraíba, Brasil, durante o período de janeiro de 2003 a dezembro de 2004. Sm = sobre macrófitas aquáticas; Pa = próximo à água no solo; Da = distante da água no solo; Ps = corpo parcialmente submerso e em solo encharcado; Fs = em fendas no solo; $\mathrm{Fr}=\mathrm{fendas} \mathrm{nas} \mathrm{rochas;} \mathrm{Sr}=$ sobre rochas; $\mathrm{St}$ = sobre troncos; $\mathrm{Sc}=$ sob troncos caídos no solo; $\mathrm{Tb}=$ touceiras de bromeliáceas; $\mathrm{Ab}=$ arbustos; $\mathrm{Ar}=$ árvores; $\mathrm{Dg}=$ dentro da água.

\begin{tabular}{|c|c|c|c|c|c|c|c|c|c|c|c|c|c|}
\hline Espécies & Sm & $\mathbf{P a}$ & Da & Ps & Fs & Fr & $\mathrm{Sr}$ & St & Sc & $\mathbf{T b}$ & $\mathbf{A b}$ & Ar & Dg \\
\hline Rhinella granulosa & & $\mathrm{X}$ & & & & & & & & & & & \\
\hline Corythomantis greeningi & & $\mathrm{X}$ & & $\mathrm{X}$ & & $\mathrm{X}$ & $\mathrm{X}$ & & & & & & \\
\hline Hypsiboas raniceps & & & & & & & & & & & $\mathrm{X}$ & & \\
\hline Phyllomedusa nordestina & $\mathrm{X}$ & & & & & & & & & & $\mathrm{X}$ & $\mathrm{X}$ & \\
\hline Scinax $x$-signatus & $\mathrm{X}$ & & & & & & & $\mathrm{X}$ & & & $\mathrm{X}$ & $\mathrm{X}$ & \\
\hline Leptodactylus caatingae & & $\mathrm{X}$ & & & $\mathrm{X}$ & & & & $\mathrm{X}$ & $\mathrm{X}$ & & & \\
\hline Leptodactylus fuscus & & $\mathrm{X}$ & & $\mathrm{X}$ & & & & & & $\mathrm{X}$ & & & \\
\hline Leptodactylus ocellatus & & $\mathrm{X}$ & & $\mathrm{X}$ & & & & & & & & & \\
\hline Leptodactylus troglodytes & & $\mathrm{X}$ & & & $\mathrm{X}$ & $\mathrm{X}$ & & & $\mathrm{X}$ & & & & \\
\hline Physalaemus albifrons & $\mathrm{X}$ & $\mathrm{X}$ & & $\mathrm{X}$ & & & & & & & & & \\
\hline Physalaemus cicada & $\mathrm{X}$ & $\mathrm{X}$ & & $\mathrm{X}$ & & & & & & & & & \\
\hline Pleurodema diplolister & & $\mathrm{X}$ & & $\mathrm{X}$ & & & & & & & & & \\
\hline Proceratophrys cristiceps & & $\mathrm{X}$ & $\mathrm{X}$ & & & & & & & & & & \\
\hline Dermatonotus muelleri & & $\mathrm{X}$ & & & & $\mathrm{X}$ & & & & & & & \\
\hline Pipa carvalhoi & & & & & & & & & & & & & $\mathrm{X}$ \\
\hline Total & 4 & 11 & 1 & 6 & 2 & 4 & 1 & 1 & 2 & 2 & 3 & 3 & 1 \\
\hline
\end{tabular}


vocalização pelas espécies registradas pode ser devido ao menor número de microhabitats disponíveis. Cardoso \& Martins (1987), Rossa-Feres \& Jim (1994) e Sawaya (1999) argumentaram que em localidades de mata, área de grande heterogeneidade ambiental, o número de microhabitats é maior ou semelhante ao número de espécies, quando comparado com localidades de áreas abertas, e esta heterogeneidade espacial é importante na determinação do número de espécies que podem explorar um determinado ambiente. Segundo Bernarde \& Anjos (1999), a sobreposição nos sítios de vocalização deve-se ao fato de que, em áreas abertas, o número de espécies é maior que o número de microambientes utilizados pelos anuros para vocalizarem.

Com relação à utilização de diferentes microambientes como sítios de vocalização, a análise de similaridade revelou a formação de cinco grupos: grupo 1 , formado por uma espécie que vocalizou dentro da água; grupo 2, espécies que vocalizaram empoleiradas nos galhos ou troncos de árvores; grupo 3, espécies que vocalizaram sobre solo seco; grupo 4, espécies que vocalizaram sobre solo encharcado ou com o corpo parcialmente submerso na água e grupo 5 , formado por aquelas que vocalizaram somente nas margens dos corpos d’água (Figura 2).

A formação de cinco grupos diferentes que utiliza- ram diferentes microambientes como sítios de vocalização, pode indicar uma partilha de recursos entre as espécies que utilizaram os corpos d'água como sítios de reprodução. Segundo Cardoso \& Haddad (1992), a ocorrência de espécies simpátricas sugere que pode existir um mínimo de diferenças ecológicas entre as espécies, o que possibilitaria sua sobrevivência em um ambiente com recursos limitados. Isto é possível devido às interações comportamentais entre as espécies, principalmente relativas à reprodução, envolvendo organização social, distribuição espacial e temporal.

Segundo Pombal (1997), a presença de anuros terrestres ou arborícolas e a heterogeneidade espacial são importantes na determinação do número de espécies que podem utilizar um determinado ambiente para a reprodução, sendo que a co-existência de diversas espécies só é possível devido à exploração de microambientes com características distintas, que juntamente com as diferenças na estrutura do canto, assumem uma importância primária para o reconhecimento específico e evitam hibridização.

Durante o período de estiagem várias espécies (33,3\%) utilizaram fendas no solo do leito seco das poças temporárias para se protegerem da dessecação durante o dia. De acordo com Carvalho (1937), estes locais de refúgio contêm umidade necessária para

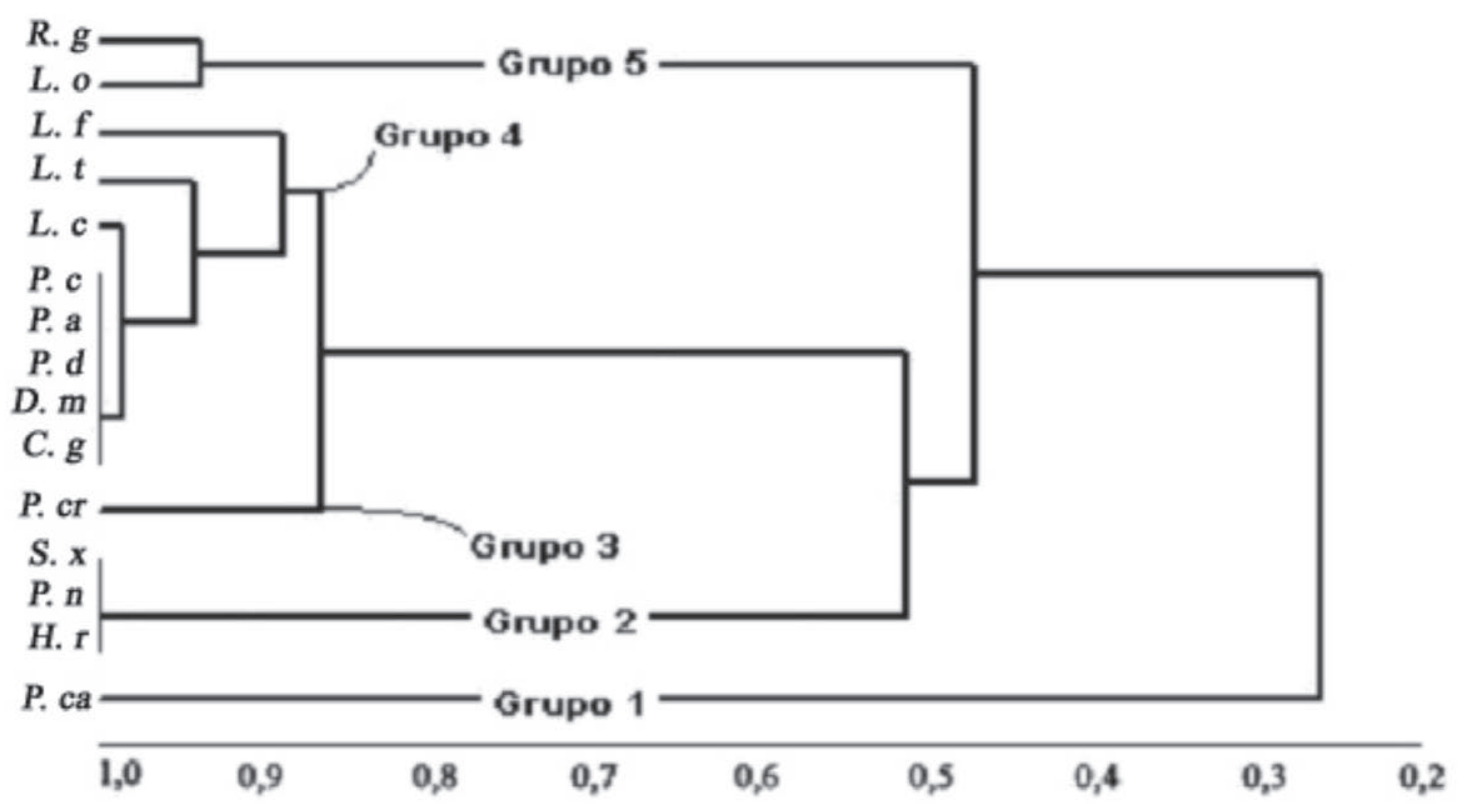

Figura 2. Similaridade da utilização de sítios de vocalização por 15 espécies de anfíbios anuros registradas em São João do Cariri e Boa Vista, Paraíba, Brasil, durante o período de janeiro de 2003 a dezembro de 2004. Legenda: $C$. gr = Corythomantis greeningi; D. $m=$ Dermatonotus muelleri; H. $r=$ Hypsiboas raniceps; L. ca = Leptodactylus caatingae; L. $f=$ Leptodactylus fuscus; L. o = Leptodactylus ocellatus; L. $t=$ Leptodactylus troglodytes; P. $a=$ Physalaemus albifrons; $P . c=$ Physalaemus cicada; $P$. ca = Pipa carvalhoi; $P . c r=$ Proceratophrys cristiceps; P. $d=$ Pleurodema diplolister; $P$. $n=$ Phyllomedusa nordestina; $R . g=$ Rhinella granulosa; $S . x=$ Scinax $x$-signatus. 
que os anuros permaneçam protegidos durante o dia evitando a perda de água por evapotranspiração.

Na Lagoa do Serrote, indivíduos de Leptodactylus ocellatus, Rhinella jimi, R. granulosa e Scinax $x$-signatus foram observados em atividade próximos as margens desta lagoa, sob a vegetação. No trecho estudado do riacho Aveloz, registrou-se a presença de indivíduos em atividade das espécies $L$. ocellatus, $R$. granulosa e $R$. jimi nas margens de pequenas poças.

No Açude dos Namorados foram observados indivíduos de L. ocellatus ao longo de suas margens e muito próximos da água. Na área da EESJC, foram observados indivíduos desta mesma espécie abrigando-se em frestas em um afloramento rochoso, 'lajeiro', o qual durante o período de chuvas serve de reservatório de água. De acordo com Paiva \& Campos (1997), nestes afloramentos de rochas intemperizadas, muitas vezes ocorrem condições microclimáticas mais úmidas, que sustentam uma comunidade de organismos bastante diversificada permitindo a sua sobrevivência em períodos mais severos.

As lagoas e poças temporárias secaram completamente durante o período de estiagem. As espécies que se reproduziram nestes corpos d’água foram encontradas refugiadas em gretas de dessecação, as quais se formam após estes ambientes secarem por completo. Tanto espécies terrestres (R. granulosa, Pleurodema diplolister, Leptodactylus caatingae e Proceratophrys cristiceps) como também arborícolas (Scinax $x$-signatus) compartilharam estes microambientes durante os meses mais secos. A profundidade em que indivíduos destas espécies foram encontrados variou entre 15 e $40 \mathrm{~cm}$. Alguns indivíduos de Scinax $x$-signatus também foram encontrados refugiando-se embaixo ou dentro de troncos caídos no chão, e indivíduos de $P$. nordestina, entre folhas de macambira (B. laciniosa).

De acordo com Carvalho (1937), os anuros da Caatinga são mais abundantes em terrenos próximos de corpos d’água temporários porque estes lugares apresentam pouca profundidade, uma maior umidade do solo, por serem encobertos pela vegetação, e abrigam uma grande diversidade de artrópodes que servirão de alimento para os adultos. Ainda segundo Carvalho (1937), os anfíbios da Caatinga também se refugiam em lugares úmidos como moitas, embaixo de pedras e entre folhas de bromélias.

Segundo Warburg (1972) e Navas et al. (2004), várias espécies de anfíbios, principalmente entre os anuros que habitam regiões áridas e semi-áridas, vivendo sob condições xéricas durante parte do ano, apresentam adaptações fisiológicas e comportamentais para evitar a perda de água por evapotranspiração e aumentar a taxa de absorção de água.

\section{ESTRATÉGIAS REPRODUTIVAS}

Cinco diferentes modos reprodutivos foram registrados. Cinco espécies (25\%) depositaram seus ovos diretamente na água (Modo 1), sete espécies (43,7\%) depositaram seus ovos em ninhos de espuma (modos 11 e 30), uma espécie (6,2\%) depositou seus ovos em folhas de árvores e arbustos (modo 24) e uma espécie aquática depositou seus ovos em depressões sobre o dorso da fêmea, com desenvolvimento indireto na água (modo 15). Três diferentes modos reprodutivos foram reconhecidos para as espécies terrestres (modos 1, 11 e 30), dois (modos 1 e 24) para as arborícolas e apenas um (modo 11) para a espécie aquática $P$. carvalhoi. Não foram observadas desovas, girinos ou jovens recém-metamorfoseados das espécies $R$. jimi e Hypsiboas raniceps (Tabela V).

A maioria das espécies observadas depositou seus ovos em ninhos de espuma, uma estratégia comum em espécies que habitam ambientes xéricos com formações vegetais abertas e com disponibilidade de água restrita a curtos períodos do ano (Cardoso \& Arzabe 1993, Duellman 1985, 1995, Arzabe 1999). A resistência à dessecação é um fator preponderante no sucesso das espécies que vivem em tais ambientes, particularmente se a distribuição das chuvas se dá de forma errática durante a estação reprodutiva. A manutenção dos ovos ou larvas em desenvolvimento dentro de ninhos de espuma aumenta a proteção destes contra predadores e o dessecamento tendo em vista o efeito de isolamento do ninho (Heyer 1969).

Ninhos em câmaras subterrâneas são usualmente construídos pelos machos e podem apresentar diferentes arquiteturas, conforme a espécie, podendo ter função de refúgio para os adultos, além de servir como local para deposição dos ovos (Arzabe \& Almeida 1997, Arzabe \& Prado 2006).

\section{PERÍODO E TURNO DE VOCALIZAÇÃO}

A maioria das espécies exibiu atividade exclusi- 
Tabela V. Modos reprodutivos adotados por 14 espécies de anfíbios anuros encontradas em São João do Cariri e Boa Vista, Paraíba, Brasil, durante o período de janeiro de 2003 a dezembro de 2004.

\begin{tabular}{|c|c|}
\hline Modo reprodutivoespécies & Hábito \\
\hline \multicolumn{2}{|c|}{ Modo 1 - Deposição dos ovos e desenvolvimento dos girinos em águas lênticas } \\
\hline Rhinella granulosa & Terrestre \\
\hline Corythomantis greeningi & Arborícola \\
\hline Scinax $x$-signatus & Arborícola \\
\hline Proceratophrys cristiceps & Terrestre \\
\hline Dermatonotus muelleri & Terrestre \\
\hline \multicolumn{2}{|c|}{$\begin{array}{l}\text { Modo } 11 \text { - Construção de ninhos de espuma sobre a superfície da água e desenvolvimento } \\
\text { dos girinos em águas lênticas }\end{array}$} \\
\hline Leptodactylus ocellatus & Terrestre \\
\hline Physalaemus albifrons & Terrestre \\
\hline Physalaemus cicada & Terrestre \\
\hline Pleurodema diplolister & Terrestre \\
\hline \multicolumn{2}{|c|}{$\begin{array}{c}\text { Modo } 15 \text { - Ovos depositados em depressões sobre o dorso da fêmea com desenvolvimento } \\
\text { indireto na água }\end{array}$} \\
\hline Pipa carvalhoi & Aquático \\
\hline \multicolumn{2}{|c|}{$\begin{array}{c}\text { Modo } 24 \text { - Deposição dos ovos sobre a vegetação a cima da água e desenvolvimento } \\
\text { larval aquático }\end{array}$} \\
\hline Phyllomedusa nordestina & Arborícola \\
\hline \multicolumn{2}{|c|}{$\begin{array}{l}\text { Modo } 30 \text { - Ninho de espuma com ovos e estágios iniciais de desenvolvimento } \\
\text { em ninhos dentro de câmaras subterrâneas, subseqüentemente a inundação, } \\
\text { girinos exotróficos em poças }\end{array}$} \\
\hline Leptodactylus caatingae & Terrestre \\
\hline Leptodactylus fuscus & Terrestre \\
\hline Leptodactylus troglodytes & Terrestre \\
\hline
\end{tabular}

vamente noturna, iniciando o turno de vocalização durante o crepúsculo. Destas, $P$. nordestina, $L$. caatingae, Physalaemus cicada, P. albifrons, Pleurodema diplolister, Proceratophrys cristiceps e $S$. $x$-signatus continuaram a atividade ao longo da noite, enquanto as outras espécies cessaram a atividade de vocalização antes de uma hora da manhã. Em nenhuma ocasião foram observados indivíduos machos vocalizando durante o dia.

Durante todo o período de estudo, as atividades reprodutivas dos anuros restringiram-se aos meses de chuva na região, o que compreendeu o período entre janeiro e junho dos anos de 2003 e 2004. L. caatingae vocalizou durante cinco meses consecutivos, apresentando dessa forma um período de vocalizações prolongado, enquanto $P$. diplolister vocalizou somente no início do mês de janeiro, apresentando uma reprodução explosiva, como observado por Cardoso \& Arzabe (1993). Nove espécies iniciaram suas atividades reprodutivas no mesmo período. Contudo, somente as espécies $L$. caatingae e $S$. $x$-signatus estenderam suas atividades reprodutivas até o mês de junho (Figura 3).

O fato da maioria das espécies ter vocalizado próximo aos corpos d'água está relacionado à sua dependência desses ambientes como sítios de oviposição, semelhante ao que foi observado por outros autores (Ainchinger 1987, Duellman \& Trueb 1994, Arzabe 1999, Bertoluci \& Rodrigues 2002, Ávila \& Ferreira 2004). A reprodução dos anfíbios anuros tende a 


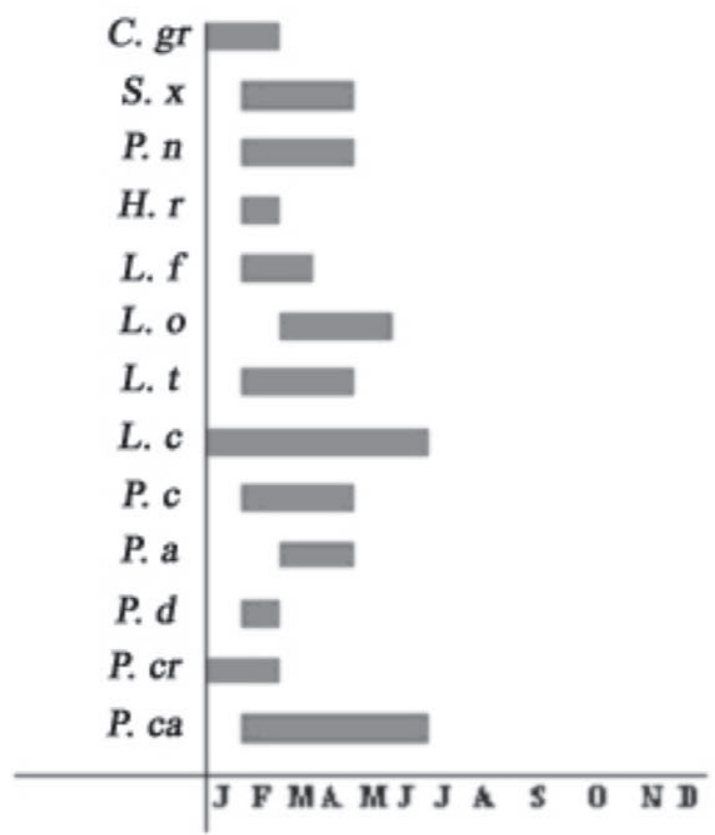

2003

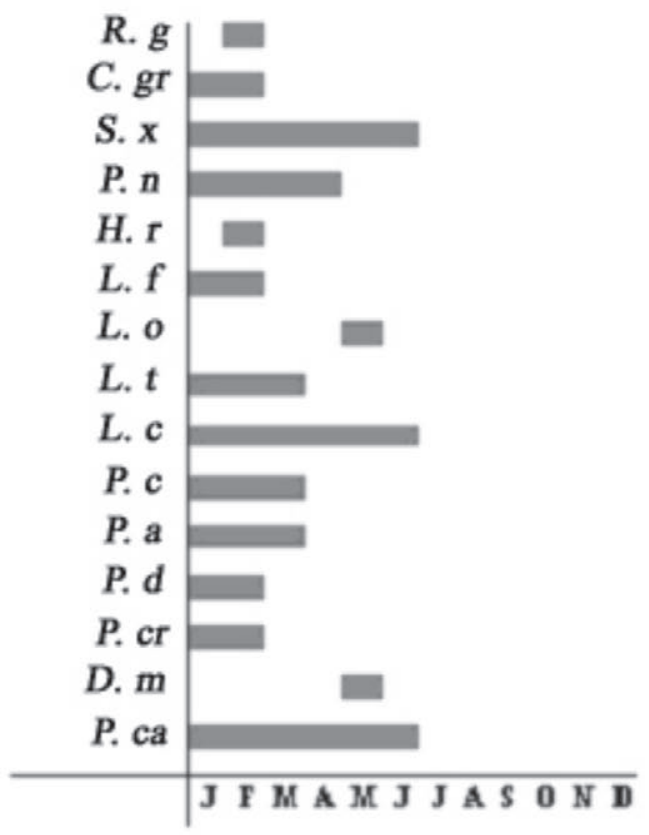

2004

Figura 3. Período de vocalização das espécies de anuros registradas durante as estações chuvosas dos anos de 2003 e 2004 , em São João do Cariri e Boa Vista, Paraíba, Brasil. Legenda: C. gr = Corythomantis greeningi; D. $m=$ Dermatonotus muelleri; H. $r=$ Hypsiboas raniceps; L. ca = Leptodactylus caatingae; $L$. $f=$ Leptodactylus fuscus; L. o = Leptodactylus ocellatus; $L . t=$ Leptodactylus troglodytes; P. $a=$ Physalaemus albifrons; P. $c=$ Physalaemus cicada; P. ca = Pipa carvalhoi; $P . c r=$ Proceratophrys cristiceps; $P . d=$ Pleurodema diplolister; $P . n=$ Phyllomedusa nordestina; . $g=$ Rhinella granulosa; S. $x=$ Scinax $x$-signatus.

ocorrer em períodos restritos do ano, condicionado principalmente pelas chuvas, visto que as larvas necessitam do meio aquático para se desenvolver. Segundo Moreira \& Barreto (1997), as ações climáticas sobre os anuros são bastante conhecidas em várias populações, nas quais as flutuações anuais nas precipitações geralmente afetam o hidroperíodo das poças, o que pode influenciar no número de indivíduos que se reproduzem neste tipo de ambiente.

A grande maioria dos anfíbios anuros apresenta período reprodutivo curto, associado à estação chuvosa que, conforme a região, pode se caracterizar por apresentar curta duração e chuvas irregulares. Mesmo em áreas onde a pluviometria anual alcança valores elevados, como na floresta amazônica, o principal fator físico que influencia o padrão de reprodução dos anuros é a distribuição das chuvas e a disponibilidade dos corpos d'água (Aichinger 1987). Nas áreas de mata atlântica no sudeste do Brasil, este padrão permanece (Pombal 1997, Bertoluci 1998, Toledo et al. 2003).

De modo geral, não foi observada diferença entre as abundâncias de anuros nas áreas estudadas em São João do Cariri e Boa Vista, durante os anos de 2003 e
2004. É possível, no entanto, que ocorram variações interanuais significativas nas abundâncias de anuros nas áreas aqui estudadas, como foi observado por Duellman (1995) para comunidades de anuros na floresta amazônica peruana.

AGRADECIMENTOS: Agradecemos ao CNPq, através do Programa de Pesquisas Ecológicas de Longa Duração (PELD), pelo suporte financeiro a esta pesquisa, e pela concessão de bolsa de Iniciação Científica a Washington Luiz da Silva Vieira; a José Roberto Lima pelo apoio na organização das viagens ao campo; a José Morais, responsável administrativo da EESJC por nos permitir usar as suas instalações, e a Gentil A.P. Filho pela ajuda nos trabalhos iniciais de campo e aos técnicos da Estação Metereológica de São João do Cariri pela franquia dos dados pluviométricos da região.

\section{REFERÊNCIAS}

AB'SÁBER, N.S. 1969. Participação das superfícies aplainadas nas paisagens do nordeste brasileiro. Geomorfologia, 19: 1-38.

AB'SÁBER, N.S. 1970. Províncias geológicas e domínios morfoclimáticos no Brasil. Geomorfologia 3: 1-26.

AB'SÁBER, N.S. 1977. Problemática da desertificação e da savanização no Brasil intertropical. Geomorfologia, 53: $1-19$.

AICHINGER, M. 1987. Annual activity patterns of anurans in a seasonal Neotropical environment. Oecologia, 71: 58-592. 
AGRA, M.F. 1996. Plantas da Medicina Popular dos Cariris Velhos. Editora A União. 125 p.

AMPHIAWEB. 2007. Amphibiaweb: Information on amphibian biology and conservation. Berkley, California. Disponível em: http://amphibiaweb.org/. (acesso em: 30.11.2007).

ARZABE, C. 1999. Reproductive activity patterns of anurans in two different altitudinal sites within the Brazilian Caatinga. Revista Brasileira de Zoologia, 16(3): 851-864.

ARZABE, C. \& ALMEIDA, C.C. 1997. Life history notes on Leptodactylus troglodytes (Anura, Leptodactylidae) in northeastern Brazil. Amphibia-Reptilia, 18: 211-215.

ARZABE, C.; SKUK, G.; SANTANA, G.G.; DELFIM, F.R.; LIMA, Y.C.C. \& ABRANTES, S.H.F. 2005. Herpetofauna da área do Curimataú, Paraíba, Pp. 259-274. In: F.S. Araújo; M.J. N. Rodal \& M.R.V. Barbosa (eds.). Análise das variações da biodiversidade do bioma Caatinga: suporte a estratégias regionais de conservação. Brasília: Ministério do Meio Ambiente. 445p.

ARZABE, C. \& PRADO, C.P.A. 2006. Distinct architectures of subterranean nests in the genus Leptodactylus of the fuscus group (Anura, Leptodactylidae). Herpetological Review, 37(1): 23-26.

ÁVILA, R.W. \& FERREIRA, V.L. 2004. Riqueza e densidade de vocalização de anuros (Amphibia) em uma área urbana de Corumbá, Mato Grosso do Sul, Brasil. Revista Brasileira de Zoologia, 21(4): 887-892.

BERNARDE, P.S. \& ANJOS, L. 1999. Distribuição espacial e temporal da anurofauna no Parque Estadual Mata dos Godoy, Londrina, Paraná, Brasil (Amphibia: Anura). Comunicações do Museu de Ciências e Tecnologia: Série Zoologia, 12: 127140.

BERTOLUCI, J.A. 1998. Annual patterns of breeding activity in Atlantic Rainforest anurans. Journal Herpetology, 32: 607611.

BERTOLUCI, J. \& RODRIGUES, M.T., 2002. Utilização de habitats reprodutivos e micro-habitats de vocalização em uma taxocenose de anuros (Amphibia) da Mata Atlântica do Sudeste do Brasil. Papéis Avulsos de Zoologia, 42(11): $287-$ 297.

NOJOSA-BORGES, D.M. \& ARZABE, C. 2005. Diversidade de anfíbios e répteis em áreas prioritárias para a conservação da Caatinga, Pp. 229-243. In: F.S. Araújo; M.J.N. Rodal \& M.R.V. Barbosa (eds.). Análise das variações da biodiversidade do bioma Caatinga: suporte a estratégias regionais de conservação. Brasília: Ministério do Meio Ambiente. 445p.

CABRAL, E.M. (Org.). 1997. Os Cariris Velhos da Paraíba. Editora Universitária e A União. 88 p.

CARDOSO, A.J. \& MARTINS, J.E. 1987. Diversidade de anuros durante o turno de vocalizações em comunidade neotropical Papéis Avulsos de Zoologia, 36(23): 279-285.

CARDOSO, A.J. \& HADDAD, C.F.B. 1992. Diversidade e turno de vocalizações de anuros em comunidade neotropical. Acta Zoológica Lilloana, 41: 93-105.

CARDOSO, A.J. \& ARZABE, C. 1993. Corte e desenvolvimento larvário de Pleurodema diplolistris (Anura: Leptodactylidae). Revista Brasileira de Biologia, 53(4): 561-570.

CARVALHO, A.L. 1937. Notas ecológicas e zoogeográficas sobre vertebrados no Nordeste Brasileiro. Revista o Campo, 12-13.

CASCON, P. 1987. Observações sobre diversidade, ecologia e reprodução na anurofauna de uma área de caatinga. Dissertação de Mestrado, UFPB, Paraíba. 64 p.

DUELLMAN, D.E. 1978. The biology of an equatorial herpetofauna in Amazonian Ecuador. Miscellaneous Publication, 65: 1-352.

DUELLMAN, W.E. 1985. Reproductive modes in anuran amphibians: Phylogenetic significance of adaptive strategies. South African Journal Science, 81: 174-178.

DUELLMAN, W.E. 1995. Temporal fluctuations in abundances of anuran amphibians in a seasonal Amazonian rainforest. Journal of Herpetology, 29(1): 13-21.

DUELLMAN W.E. \& TRUEB, L. 1994. Biology of amphibians. Johns Hopkins University Press. 789 p.

FROST, D.R. 2007. Amphibians Species of the World: an online reference. Version 3.0. Accessible at: http://www.research.amnh. org/herpetology/amphibia/index.php. (acesso em 30.11.2007).

HADDAD C.F.B. \&, PRADO, C.P.A. 2005. Reproductive modes in frogs and their unexpected diversity in the Atlantic Forest of Brazil. BioScience, 55(3): 207-217.

HEYER, W.R. 1969. The adaptive ecology of the species groups of the genus Leptodactylus (Amphibia, Leptodactylidae). Evolution, 23: 421-428.

HEYER, W.R. 1988. On frog distribution patterns East of the Andes. Pp. 245-273. In: P.E. Vanzolini \& W.R. Heyer. (eds.). Proceedings of a workshop on Neotropical distribution patterns. Academia Brasileira de Ciências, 488 p.

HEYER, W.R., \& JUNCÁ, F.A. 2003. Leptodactylus caatingae, a new species of frog from eastern Brazil (Amphibia: Anura: Leptodactylidae). Proceeding of the Biological Society of Washington, 116(2): 317-329.

KREBS, C.J. 1989. Ecological Methodology. Harper \& Row, New York. 652 p.

LEWINSONHN, T.M. \& PRADO, P.I. 2002. Biodiversidade brasileira: síntese do estado atual do conhecimento. Editora Contexto. São Paulo. 175 p.

MOREIRA, G. \& BARRETO, L. 1997. Seasonal variation in 
nocturnal calling activity of a savanna anuran community in central Brazil. Amphibian-Reptilia, 18: 49-57.

MMA (Ministério do Meio Ambiente), 2002. Avaliação e Ações Prioritárias para a Conservação da Biodiversidade da Caatinga. Brasília, DF. 36 p.

NAVAS, C.A.; ANTONIAZZI, M.A. \& JARED, C. 2004. A preliminary assessment of anuran physiological adaptation to the Caatinga, a Brazilian semi-arid environment. International Congress Series, 1275: 298-305.

PAIVA, M.P. \& CAMPOS, E. 1997. Fauna do Nordeste do Brasil: Conhecimento científico e popular. Banco do Nordeste do Brasil. Fortaleza, Ceará. 273 p.

POMBAL, J.P. 1997. Distribuição espacial e temporal de anuros (Amphibia) em uma poça permanente na Serra de Paranapiacaba, Sudeste do Brasil. Revista Brasileira de Biologia, 57(4): 583-594.

RODRIGUES, M.T. 2002. A fauna de répteis e anfíbios. Pp.: 144-145. In: Ministério do Meio Ambiente. Biodiversidade brasileira: Avaliação e identificação de áreas prioritárias para a conservação, utilização sustentável e repartição de benefícios de biodiversidade brasileira. Brasília, DF.

ROSS, J.L.S. (Org.). 1998. Geografia do Brasil. EDUSP - Editora da Universidade de São Paulo, São Paulo. 549 p.

ROSSA-FERES, D.C. \& JIM, J. 1994. Distribuição sazonal em comunidades de anfíbios anuros na região de Botucatu, São Paulo. Revista Brasileira de Biologia, 54(2): 323-334.

SAWAYA, R.J. 1999. Diversidade e densidade altitudinal da anurofauna de serrapilheira da Ilha de São Sebastião. Dissertação de Mestrado, Universidade de São Paulo. Brasil $65 \mathrm{p}$.

SBH (Sociedade Brasileira de Herpetologia), 2007. Lista das espécies de anfíbios do Brasil. Disponível em: http://www2. sbherpetologia.org.br/checklist/anfibios.htm. (acesso em: 30.11.2007).

SCOTT, N. \& WOODWARD, B.D. 1994. Surveys at breeding sites. Pp. 118-25. In: W.R. Heyer; M.A. Donnelley; R.W. McDiarmid; L.C. Hayek \& M.S. Foster (eds.). Measuring and monitoring biological diversity: standard methods for amphibians. Smithsonian Institution Press, Washington. 364 p.

STEVAUX, M.N. 1993. Estratégias reprodutivas de Mabuya sp. (Sauria: Scincidae): um padrão de reprodução para o Gênero na Região Neotropical. Revista Nordestina de Biologia 8(1): 61-86.

TOLEDO, L.F.; ZINA, J. \& HADDAD, C.F.B. 2003. Distribuição Espacial e Temporal de uma Comunidade de Anfíbios Anuros do Município de Rio Claro, São Paulo, Brasil. Holos Environment, 3(2): 136-149.

VIEIRA, W.L.S.; ARZABE, C. \& VIEIRA, K.S. 2006. Amphibia,
Leptodactylidae, Leptodactylus caatingae: geographical distribution extension. Check list, Journal of Species lists and Distribution, 2: 55-56.

WARBURG, M.R. 1972. Water economy and thermal balance of Israeli and Australian amphibians from xeric habitats. Symposia of the zoological Society of London, 31: 79-111.

Submetido em 25/06/2007 Aceito em 07/12/2007 